\title{
Prognostic value of dynamic follow-up of oldest children in the regression phase of ROP
}

\author{
Utegenova Gulnar², Teleuova Tynyskul ${ }^{3}$, Gabaydulina Assiya², Asanbaeva Diana ${ }^{2}$, Karin Bekturgan², Tortaeva \\ Gulnar $^{2}$, Hasanova Liliya ${ }^{1}$
}

${ }^{I}$ Republican diagnostic center of the corporate fund "UMC», Astana, Kazakhstan

${ }^{2}$ National research center for maternal and child health of the corporate fund «UMC», Astana, Kazakhstan

${ }^{3} M U$ of Kazakhstan of CE, Almaty, Kazakhstan

УДК 617.7 ОФТАЛЬМОЛОГИЯ. ГЛАЗНЫЕБОЛЕЗНИ

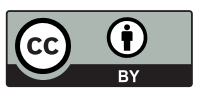

This work is licensed under a Creative Commons Attribution 4.0 International License

J CLIN MED KAZ 2017; 3(45 SUPPL 3):154-158

Corresponding author: Утегенова Г.Н., Национальный научный центр материнства и детства корпоративного фонда «UMC», Адрес: пр.Туран, 32, г.Астана, Казахстан, тел.: +77052540414,

e-mail: utegenovag@gmail.com

\section{ABSTRACT}

In this article, we analyzed publications about on late complications of cicatricle retinopathy of prematurity, as well as on possible diagnostic and therapeutic measures for preserving visual functions. Materials were taken from published articles in accessible periodicals and literature, as well as using the resources of PubMed, Medscape. Experts agree on the need for lifelong ophthalmologic monitoring of patients born prematurely. The frequency of an ametropia, a myopia, an astigmatism, a strabismus, an amblyopia, vitreoretinal changes is high in this category of patients.

Keywords: prematurity, RN - retinopathy of prematurity, detachment of the retina.

\section{ТҰЖЫРЫМДАМА}

ШАЛА ТУЫЛҒАН БАЛАЛАРДЫ МЕРЗІМНЕН БҰРЫН ТУЫЛҒАН БАЛАЛАРДЫН РЕТИНОПАТИЯНЫН БЕРІШ/РЕГРЕССИВТІ КЕЗЕНІНДЕ ДИНАМИКАЛЫҚ БАҚЫЛАУДЫН БОЛЖАМДЫҚ ҚҰНДЫЛЫҒЫ (ӘДЕБИЕТКЕ ШОЛУ)

Утегенова Г. ${ }^{2}$, Телеуова Т. ${ }^{3}$, Габайдулина А. ${ }^{2}$, Асанбаева Д. ${ }^{2}$, Карин Б. ${ }^{2}$, Тортаева Г. ${ }^{2}$, Хасанова Л. ${ }^{1}$

'«UMC» корпоративтік корының Республикалық диагностикалық орталығы, Астана, Қазақстан

${ }^{2}$ «UMC» корпоративтік қорының Ана мен бала ұлттық ғылыми орталығы, Астана, Қазақстан

${ }^{3}$ «Қазақ медициналық үздіксіз білім беру университеті» АҚ, Алматы, Қазақстан

Осы мақалада мерзімнен бұрын туылған балалардыңтыртықтықретинопатияның кешірек болатын асқынулары, сонымен қатар көру функциясын сақтау үшін ықтимал диагностикалық және емдік шаралар туралы жариялымдар шолуына талдау жасалады. Материалдар жарияланған мерзімді баспада және әдебиетте қолжетімді мақалалардан, сонымен бірге PubMed, Medskype ресурстарынан алынды.

Мамандардың мерзімнен бұрын туылған науқастарды өмір бойы офтальмологиялық бақылау қажеттілігі туралы пікірлері ортақ. Аметропия, миопия, астигматизм, қилылық, амблиопия, витреоретиналдық өзгерістердің жиілілігі сырқаттардың осы тобында жоғары болады. бөлімі.

Маңызды сөздер:шала ту, RN - шала туған кездегі ретинопатия, сетчатка

PЕЗЮME

ПРОГНОСТИЧЕСКАЯ ЦЕННОСТЬ ДИНАМИЧЕСКОГО НАБЛЮДЕНИЯ ЗА НЕДОНОШЕННЫМИ ДЕТЬМИ В РУБЦОВУЮ/ РЕГРЕССИВНУЮ ФАЗУ РЕТИНОПАТИИ НЕДОНОШЕННЫХ Утегенова Г. ${ }^{2}$, Телеуова Т. ${ }^{3}$, Габайдулина А. ${ }^{2}$, Асанбаева Д. ${ }^{2}$, Карин Б. ${ }^{2}$, Тортаева $\Gamma_{.}^{2}$, Хасанова Л. ${ }^{1}$

'Республиканский диагностический центр корпоративного фонда «UMC», Астана, Казахстан ${ }^{2}$ Национальный научный центр материнства и детства корпоративного фонда «UMC», г. Астана, Казахстан ${ }^{3} \mathrm{AO}$ «Казахский медицинский университет непрерывного образования», Алматы, Казахстан

В данной статье проведен анализ обзора публикаций о поздних осложнениях рубцовой/регрессивнойретинопатии недоношенных, а также о возможных диагностических и лечебных мероприятиях для сохранения зрительных функций. Материалы взяты из опубликованных статей в доступной периодической печати и литературе, а также с использованием ресурсов PubMed, Medskype. Специалисты едины во мнении о необходимости пожизненного офртальмологического наблюдения за пациентами, рожденными недоношенными. Частота аметропии, миопии, астигматизма, косоглазия, амблиопии, витреоретинальных изменений высока у данной категории пациентов.

Ключевые слова: недоношенность, РН -ретинопатия недоношенных, отслойка сетчатки. 


\section{Введение}

Более 50000 детей в год по всему миру до сих пор становятся слепыми или слабовидящими по причине ретинопатии недоношенных (PH)[1]. По статистическим данным, в нашей стране ежегодно рождается около 20 тысяч недоношенных новорожденных, из которых 15\% (> 3000 детей) составляют дети с очень низкой $(1000-1499$ г) и экстремально низкой(500-999 г) массой тела при рождении. Раннее выявление активной фазы РН, своевременное лечение в пороговых стадиях являются значимыми задачами для неонатологов и офтальмологов республики, поэтому в 2011-2012гг. были внедрены основные этапы управления заболеванием: скрининг, диагностика, а также «золотой стандарт» лечения пороговой РН - лазерная коагуляция аваскулярной сетчатки. Эффективность лечения достигла от 93 до 96 \% [2]. Офтальмологи «ННЦМД» в 2011-2013гг. в рамках научного проекта приняли активное участие во внедрении диагностических и лечебных мероприятий при РН в Республике. С 2012 года пролечено более 300 детей (более 600 глаз). Эффективность составила 95-96\%. В настоящее время в Отделе Педиатрии КФ «UMC» РДЦ продолжается консультативный прием для недоношенных детей разного возраста из г. Астана и регионов республики. Здесь наблюдаются дети после оперативно- и самоиндуцированного регресса заболевания, а также после витреоретинальных операций. Специалисты отмечают высокий процент диагностирования нарушений рефракции, косоглазия, кортикальных нарушений у наблюдаемых детей, которые выявляются в раннем и позднем возрасте. Тревогу вызывает информация офтальмологов других стран о том, что рубцовая РН в более позднем периоде имеет дальнейшее прогрессирование патологических витреоретинальных изменений, что ставит этих детей в группу риска по развитию отслоек сетчатки на протяжении всей их жизни (InternationalCommitteefortheClassificationof ROP, 1987; Larson E.K., Holmstram G.E., 2005; Loone E., O'Keefe M., 2006; Асташева И.Б., 2001; Катаргина Л.А., Коголева Л.В., 2002; Рудник А.Ю., Сомов Е.Е., 2003-2013).

Цель данной статьи: Провестианализ публикаций, посвященных поздним осложнениям рубцовой/ регрессивнойретинопатии недоношенных, а также о возможных диагностических и лечебных мероприятиях для сохранения зрительных функций.

Материалы анализа. Данный обзоро распространенности рефракционных нарушений, витреоретинальных осложнений, в когорте детей, рожденных недоношенными,основан на анализе статей, опубликованных в доступной периодической печати, а также с использованием ресурсов PubMed, Medskype.

Результаты. Офтальмологи из Филадельфии, США еще в 1998 году провели сравнительный анализ распространенности миопии среди 827 детей, рожденных недоношенными с массой тела при рождении менее 1251г., «с» и без РН. Обследование проводилось в возрасте от 3 месяцев до 5,5 лет. Рефрактометрия детям исследована в возрастах: 3 месяцев, 1год, 2 года, 3,5, 4,5 и 5,5 года жизни. Авторы утверждают, что диагностирование миопии прямо пропорционально тяжести заболевания РН. К 1 году миопия диагностирована в $21,1 \%$ случаях, в 4,5 года $15,1 \%$ случаях. Выявлена закономерность выявления высокой миопии у детей, имевших при рождении экстремально малую массу, перенесших РН, а также у которых в период между 3 месяцами и 1 годом жизни была выявлена миопия начальных степеней [4].
Индийские офтальмологи в 2003 году сообщили, что высокая миопия, миопический астигматизм, анизометрическая амблиопия и косоглазие возникают у данной категории пациентов с или без РН. Исследователи утверждают, что более серьезные проблемы, такие как катаракта, глаукома и поздние отслойки сетчатки или кровоизлияние в стекловидное тело встречались в глазах, обработанных лазером при РН 1 типа. Также специалисты подчеркивают, что у недоношенных детей наблюдается «замедленное визуальное созревание» и очевидная неспособность видеть и распознавать предметы (часто ошибочно диагностируемая как атрофия зрительного нерва или слепота) из-за незрелости и расстройств центральной нервной системы [5].

Офтальмологи из Швеции опубликовали результаты проведенного долгосрочного 3,5 летнего наблюдения. Каждые 6 месяцев, за развитием рефракции наблюдались 248 недоношенных детей с массойтела при рождении $\leq 1500$ г). Установлено, что миопия в возрасте 6 месяцев у всех обследуемых составила 8\%. В возрасте 2,5 лет - в среднем $10 \%$, однако в группе послеоперационных к 30 месяцам жизни повышалась до 30-40\%. Частота астигматизма была через 6 месяцев $52 \%$ и $26 \%$ через 30 месяцев, процент не менялся от наличия проведенного лечения[6].

Сотрудники Московского НИИ глазных болезней имени Гельмгольца проанализировали клиникофункциональное состояние глаз 130 преждевременно родившихся детей (260) по достижении ими возраста 6-18 лет (средний возраст 9,5 года), когда было возможно проведение углубленного функционального обследования. Все пациенты родились преждевременно на 25-34-й неделе гестации с массой тела 640-2100 г. Авторы отмечают многофакторность наблюдаемых нарушений зрения у недоношенных детей, утверждают, что своевременная коррекция аметропий, плеоптическое лечение, адекватная медикаментозная терапия и своевременная лазеркоагуляция сетчатки позволяют развить и сохранить зрительные функции у значительного числа пациентов с регрессивной РН. Было установлено, что зрительные функции у детей с РН в отдаленный период зависят не только от степени остаточных изменений, но и от наличия сопутствующих рефракционных, глазодвигательных нарушений, в том числе и от патологии ЦНС. Обращено внимание на полиморфизм рубцовой или регрессивной $\mathrm{PH}$, на возможность развития поздних осложнений, причем при любой степени остаточных изменений, требующей организации диспансерного наблюдения и проведения курсов лечения[7].

Сотрудники из одесского «Института глазных болезней и тканевой терапии им. В.П. Филатова» Украины опубликовали данные сравнительного исследования доношенных и недоношенных детей с самопроизвольным регрессом РН или после лазерного лечения заболевания. Исследователи сделали выводы, что статистически достоверно миопическая рефракция встречалась чаще у детей с прогрессирующей РН (после проведенной лазерной коагуляции). Так среди числа недоношенных детей при рождении диагностировались: миопия слабой степени (12 глаз, 30,0\%) и высокой степени (10 глаз, 25,0\%), реже средней степени (4 глаза, 10,0\%)[8].

Офтальмологи из Королевского офтальмологического госпиталя Манчестера сообщили о результатах проведенного ретроспективного изучения анамнеза 32 пациентов (40 глаз), имевшие в отслойку сетчатки на фоне регрессивной РН в старшем возрасте. Все исследуемые 
являлись преждевременно рожденными в период между 1989 и 2001 годами, имели после рождения активную РН, но не подвергшиеся оперативному лечению заболевания по причине самоиндукции заболевания. При рождении имели массу тела от 730г. до 1600г. Как сообщают авторы, у трех детей в анамнезе после рождения наблюдалось внутри желудочковое кровоизлияние, связанное с недоношенностью, и у двух из этих пациентов некротический энтероколит. На момент отслойки сетчатки средний возраст исследуемых составлял 22,3 года (диапазон 8-59 лет), из которых имевшие возраст 8-20 лет - 62,5\% и 32-45 лет-32,5\%. Миопия была зарегистрирована в 90\% глаз (в среднем 5,9 диоптрии, диапазон от 0 до -12 диоптрий). У большинства пациентов $(82,5 \%)$ на момент тягового синдрома отмечались патологический ход папилломакулярного пучка, катаракта $10 \%, 30 \%$ - косоглазие, 27,5\%- нистагм. Также исследователи наблюдали в пятнадцати глазах (37,5\%) признаки периферической ретинальной дегенерации сетчатки, а в девяти глазах (22,5\%) периферические пигментные изменения сетчатки. [9]

Другая группа из Индии сообщает о ретроспективном исследовании (с февраля1999г. по январь 2002г.), проведенном у 105 детей (111глаз) с ювенильной регматогенной отслойкой сетчатки. Все дети при рождении были недоношенными. Средний возраст составлял 13 лет. Авторы отмечают о факторах, провоцирующих отслойку сетчатки у несовершеннолетних, это миопия $(41,4 \%)$ и контузия глазного яблока (45\%) [10].

Исследователи из Италии опубликовали результаты наблюдения за динамикой рефрактогенеза, глазодвигательных нарушений и офтальмоскопии среди детей, рожденных маловесными (< 1500г.), с низким сроком гестации при рождении $(<32$ недель), в возрастном промежутке от 1 года до 6 лет. Испытуемые были разделены на группы. В 1 группе наблюдались дети без РН, всего 217 детей, во 2-й группе- 28 детей с РН начальных стадий, в 3-й группе-16 детей, у которых была диагностирована тяжелая РН. В 1 год жизни близорукость развилась в 1 группе в 6,8\%, во 2-й - 18\%, в 3-й - 40,6\%; дальнозоркость $-39,2 \%, 28 \%, 22 \%$; астигматизм- 53,9\%, 53,4\%, 37,4\% соответственно. В 6 лет - близорукость- 7,4\%, 10,8\% и $28,4 \%$; дальнозоркость - 62\%, 48,3\% и 40,5\%; астигматизм - $30,6 \% ; 40,9 \%$ и $31,1 \%$; косоглазие - $11,5 \%, 25 \%$ и $56,25 \%$. По окончании исследования авторами был сделан вывод, что в 6 лет наблюдается увеличение диагностирования дальнозоркости, косоглазия во всех группах по сравнению с детьми в 1 год. Отмечается частая регистрация миопии и косоглазия в группе детей имевших в анамнезе легкую и тяжелую РН, по сравнению с недоношенными детьми без $\mathrm{PH}$, и риск развития этих расстройств значительно увеличивался с тяжестью заболевания[11].

Офтальмологи из Белоруссии в 2011 году доложили результаты анализа отдаленных исходов РН по данным офтальмоскопии. Исследователи проанализировали клинико-функциональное состояние глаз 71 детей с рубцовой фазой РН в возрасте от 9 месяцев до 17 лет. Все исследуемые дети родились недоношенными с массой тела от 570 до 2500 граммов, на 25-38 неделе гестации. Офтальмологи отмечают, что наиболее грозное осложнение у детей с рубцовой РН, приводящее к потере зрения и являющееся ургентным состоянием - развитие поздней отслойки сетчатки. На глазах с риском поздней отслойки сетчатки были выявлены периферические витреоретинальные дистрофии, витреальные мембраны, витреоретинальные тракции, ретинальные разрывы. Авторы отмечают, что высокая миопия и периферическая решетчатая дистрофия сетчатки также представляют высокий риск развития отслойки сетчатки, так как у 16 наблюдаемых возникли поздние отслойки сетчатки. В $60 \%$ случаев у исследуемых детей наблюдалась миопия высокой и средней степени, астигматизм; у 70\% детей выявлено косоглазие - паралитическое и вторичное, из-за эктопии макулы, у 30 \% детей был нистагм как глазного, так и центрального генеза[12].

Авторы из Дании провелимультицентровое ретроспективное исследование в университетской клинике Копенгагена. Они сообщили о проведенном офтальмологическом исследовании 31 пациентам, ранее недоношенных при рождении. У 14 пациентов в диапазоне от 6 до 46 лет, наблюдались различные витреоретинальные нарушения, в том числе отслойка сетчатки и гемофтальм. В 12 случаях в диапазоне от 7 до 58 лет нарушения наблюдались в переднем отрезке глаз, в четырех глазах в связи со слепотой и болевого синдрома проведена энуклеация и экзентерация. У 20 пациентов зрительные функции с детства были низкие. Авторы предположили гипотезу о том, что помимо структурной уязвимости в глазах недоношенных новорожденных, ограниченного функционального резерва в связи с незрелостью при рождении зрительного анализатора, существует сниженная резистентность к более поздним офтальмологическим событиям, таким как травма, заболевание или влияние возраста[13].

Российские офтальмологи Военно-медицинской академии им. С.М. Кирова г. Санкт-Петербурга опубликовали результаты проведенного 10 летнего наблюдения (20032013г.). Динамическое офтальмологическое обследование прошли 276 детей (552 глаза) в возрасте от 1 года до 18 лет, имевшие в анамнезе активную РН. У 113 пациентов (226 глаз) была проведена трансконъюнктивальная лазерная и/или криокоагуляция аваскулярных зон сетчатки. У остальных 163 детей (326глаз) была зафиксирована самоиндукция активной РН. Авторы установили, что одним из основных проявлений витреоретинальных осложнений у детей в рубцовом периоде РН является формирование различного вида пролиферации. Специалисты утверждают, что, если в начале наблюдения частота диагностированных отслоек сетчатки непревышала 32\% (72 пациента, 115 глаз), то уже через 7-9 лет наблюдений локальные периферические отслойки сетчатки были зафиксированы у каждого второго ребенка. Авторы резюмируют,что рубцовый период РН характеризуется медленным, но неуклонно прогрессирующим течением и что дети с ретинопатией недоношенных в отдаленный периодзаболевания нуждаются в пристальном динамическом наблюдении с обязательным детальным осмотром всех участков периферии глазного дна[14.]

Южнокорейские офтальмологи в 2000г. опубликовали результаты исследования особенностей рефрактогенеза, а также роли преломляющих сред глаза в развитии миопии у недоношенных детей. Авторы наблюдали за 65детьми (125 глаз), которые не имели признаки заболевания в период скрининга и мониторинга на РН, а также дети с начальными степенями заболевания, в том числе после проведения криотерапии. Определение рефракции проводилось в состоянии циклоплегии детям в возрасте 6 месяцев, 3 года и в 6 лет. Специалисты выявили, что у детей с рубцовой PH, 104 глаз имели тенденцию к развитию миопии. Также особенностью явилось то, что в 6 лет недоношенные дети с 
миопической рефракцией демонстрировали более мелкие размеры глубины передней камеры, увеличенные переднезадние размеры хрусталиков и глаз [15].

Позже в 2004 году о риске отслойки сетчатки у детей с регрессивной РН в старшем возрасте сообщили офтальмологи из Сеула. Специалисты провели многоцентровое исследование, наблюдая за рожденными недоношенными детьми в возрасте от 2 до 15 лет. В ходе наблюдения были выявлены особенности клинического течения ретинальных изменений после хирургического лечения РН, осложнений заболевания в виде возникшей отслойки сетчатки. Авторы утверждают о том, что визуальные прогнозы при отслойке сетчатки в детском возрасте значительно ниже, чем у взрослых пациентов с регрессивной РН, обращают внимание на эффективность частого офтальмологического наблюдения за детьми, особенно у невербальных детей [16].

\section{Обсуждение и выводы}

Итак, специалисты едины во мнении о необходимости пожизненного офтальмологического наблюдения за пациентами, рожденными недоношенными. Частота аметропии, миопии, астигматизма, косоглазия, амблиопии, витреоретинальных изменений высока у данной категории пациентов. Исследователи утверждают, что диагностирование миопии прямо пропорционально тяжести перенесенной РН в младенчестве. Проведение ретиноскопии в состоянии циклоплегии в период с 3 месяцев до 1 года актуально. Многие исследователи отмечают о патологических витреоретинальных изменениях, диагностирующийся в более старшем возрасте у пациентов, ранее рожденных недоношенными [7, 9, 13, 14, 16]. Необходимость в динамическом наблюдении, для проведения своевременной коррекции аметропий, плеоптического лечения, адекватной медикаментозной терапии и своевременного лечения, являются оправданными и для казахстанских офтальмологов.

На основании данных литературы можно сделать следующие выводы:

1. Рубцовый период РН характеризуется медленным, но неуклонно прогрессирующим течением. У таких детей помимо рефракционных и визуальных нарушений возможны витреоретинальные изменения сетчатки, которые являются угрозой потери зрительных функций.

2. Дети с РН оперированные и не оперированные в отдаленный период заболевания нуждаются в пристальном динамическом наблюдении обязательным детальным осмотром всех участков периферии глазного дна, так как находятся в группе риска по развитию отслоек сетчатки на протяжении всей жизни.

3. Необходимо внедрять современные методы морфометрии и дифференцировки патологических изменений с применением высокотехнологичных офтальмологических аппаратур, что позволит значительно повысить качество диагностики заболеваний заднего отрезка глаза у детей с рубцовой РН.

4. Необходимо изучить клинико-функциональные критерии неблагоприятного течения рубцовой РН, которые будут иметь значение для прогноза и выбора оптимальной тактики лечения поздних осложнений, как профилактики детской слепоты.

\section{Литература:}

1. GilbertC. Retinopathyofprematurity: a global perspective of the epidemics, population of babie satrisk and implications for control. EarlyHum. Dev. 2008; 84: 77-82.

2. Botabekova T.K., SharipovaA.U. Retinopatija nedonoshennyh- social'no-znachiemaja problema Respubliki Kazahstan (Retinopathy of prematurity - socially significant problem of the Republic of Kazakhstan) [in Russian]. Rossijskaja detskaja oftal'mologija. 2015. 11-14.

3. Botabekova T.K., Sharipova A.U.Organizacijaspecializirovannojoftal'mologicheskojpomoshhinovorozhdennym s retinopatiejnedonoshennyh $\mathrm{v}$ uslovijahmegapolisa (Organization of specialized ophthalmic care for newborns with retinopathy of prematurity in a megapolis) [in Russian]. Rossijskajadetskajaoftal'mologija. 2015; 9-11.

4. Quinn GE, Dobson V, Kivlin J, Kaufman LM, Repka MX, Reynolds JD, Gordon RA, Hardy RJ, Tung B, Stone RA.Prevalence of myopia between 3 months and $51 / 2$ years in preterm infants with and without retinopathy of prematurity. Cryotherapy for Retinopathy of Prematurity Cooperative Group. Ophthalmology. 1998;105(7):292-300.

5. Jalali S, Anand R, Kumar H, Dogra MR, Azad R, Gopal L.Programme planning and screening strategy in retinopathy of prematurity. Indian J.Ophthalmol. 2003;51(1):89-99.

6. HolmströmG, AzaziM, KugelbergU. Ophthalmological long-term follow up of preterm infants: a population based, prospective study of the refraction and its development. Br.J.Ophthalmol. 1998;82:1265 \pm 1271

7. Katargina L., Kogoleva L., Belova M., MamakaevaI.;Refrakcijai kosoglazie u detej c retinopatiej nedonoshennyh v sravnenii s donoshennymi mladencami (Clinical symptoms and factors leading to visual impairment in children with cicatricial and regressive retinopathy of prematurity) [in Russian]. RMZh «KlinicheskajaOftal'mologija». 2009, 108-111.

8. Bojchuk I.M., Kacan S.V., Stojanova E.S., Zaichko E.S.; Refrakcijai kosoglazie u detej c retinopatiej nedonoshennyh v sravneniis donoshennymi mladencami (Refraction and strabismus in children with retinopathy of prematurity in comparison with full-term infants) [in Russian]. Retinopatijanedonoshennyh. 2013. 178-180.

9. Tufail A, Singh AJ, Haynes RJ, Dodd CR, McLeod D, Charteris DG; Late onset vitreoretinal complications of regressed retinopathy of prematurity. Br J Ophthalmol. 2004; 88 (2):243-249.

10. NagpalM, Nagpal K, Rishi P, Nagpal PN. Juvenile rhegmatogenous retinal detachment.Indian Journal of Ophthalmology. 2004, 52(4):297-302. 
11. Al OumM., Donati S., Cerri L., Agosti M.,AzzoliniC.Ocular alignment and refraction in preterm children at 1 and 6 years old.in Ophthalmol. 2014; 8: 1263-1268.

12. Ivanova V.F., Gerasimenko E.V., Dovzhenko E.A.; Klinikai lechenie detej s rubcovojretinopatiej nedonoshennyh (Clinic and treatment of children with scar retinopathy of prematurity) [in Russian].2011, 162-168.

13. Hans C. Fledelius and Hanne Jensen; Late subsequent ocular morbidity in retinopathy of prematurity patients, with emphasis on visual loss caused by insidious 'involutive' pathology: an observational series. Acta Ophthalmol. 2011;89(4):316-339.

14. RudnikA.Ju., Mal'cev D.S.; OOsobennosti proliferacii i dinamika vitreoretinal'nyh izmenenij u detej s retinopatiej nedonoshennyh v otdalennyj period razvitija zabolevanija (Features of the proliferation and dynamics of vitreoretinal changes in children with retinopathy of prematurity in the late period of the disease) [in Russian]. 2013. 204-208.

15. ChoiM. Y., ParkI. K., and YuY. S.Long term refractive outcome in eyes of preterm infants with and without retinopathy of prematurity: comparison of keratometric value, axial length, anterior chamber depth, and lens thickness. Br J Ophthalmol.2000; 84(2): 138-143.

16. Park KH, Hwang JM, Choi MY, Yu YS, Chung H. Retinal detachment of regressed retinopathy of prematurity in children aged 2 to 15 years. Retina. $2004 ; 24(3): 368-375$. 